\title{
GONÇALVES, ANTÓNIO CUSTÓDIO. A HISTÓRIA REVISITADA DO KONGO E DE ANGOLA. LISBOA: EDITORIAL ESTAMPA, 2005.
}

\author{
Rosana Gonçalves \\ Mestranda em História Social FFLCH-USP
}

António Custódio Gonçalves é sociólogo e professor catedrático do departamento de Geografia da Universidade do Porto, onde dirige o Centro de Estudos Africanos (CEAUP), coordenando um importante periódico sobre África, a Africana Studia. Há anos debruçado sobre temáticas africanas, António Custódio Gonçalves sintetiza muitas das complexas questões sobre a história do Kongo ${ }^{1}$ e Angola nesta publicação.

O autor recorre em suas análises a diversos tipos de fontes documentais e se considera em posição privilegiada de interpretação por ter tido a oportunidade de trabalhar por muitos anos na região e assim ter vivenciado pessoalmente alguns eventos peculiares da sociedade angolana que, segundo ele, têm continuidade na longa duração. Parece-lhe que os mecanismos de base da sociedade Kongo pouco se modificaram ao longo do tempo, o que lhe permite o cruzamento de fontes escritas em diferentes épocas com seu trabalho de campo, por meio do qual pôde ouvir testemunhos que o ajudaram a compor um panorama social e político da região.

Custódio Gonçalves preocupa-se em esmiuçar as estruturas sociais e políticas que se formam ao longo do tempo, tendo sobre as fontes uma visão de sociólogo, na medida em que não destaca os eventos históricos que as cercam. Sua ênfase

\footnotetext{
${ }^{1}$ Muitos estudiosos utilizam Kongo para diferenciar, no tempo e no espaço, o chamado "reino do Kongo" das localidades geográficas que hoje conhecemos: Congo e República Democrática do Congo.
} 
dá-se no cuidado em decifrar os mecanismos de associação dos membros de um determinado grupo, as relações entre diferentes clãs e as alianças políticas.

Seu objeto de estudo no livro é a sociedade Kongo e Angola do início do século XVI ao início do XVIII, acrescentando um último capítulo que avança para as questões atuais da sociedade angolana pós-colonial. A área cultural abrange os chamados "grupos Kongo", ou seja, chefaturas estabelecidas no entorno de Mbanza Kongo, localidade relativamente móvel identificada nos relatos de viajantes e missionários como "reino do Kongo".

O livro divide-se em três partes, a primeira diz respeito à caracterização do sistema de parentesco Kongo e sua gênese, a segunda parte analisa as alianças e constantes mudanças na sucessão e herança da sociedade Kongo e a terceira contempla um movimento de inovação social e reestruturação de poder, o que entendemos tratar-se de um período que inicia-se em princípios do século XVIII. Mas a divisão estabelecida pelo autor não gera partes cronologicamente lineares, ainda que tenhamos feito um esforço para detectar os períodos históricos, seu objetivo não está nessa demonstração.

Custódio Gonçalves dialoga com diversos pesquisadores dedicados ao Kongo, criticando os estudos que tentam supervalorizar influências externas, ao mesmo tempo em que faz questão de enfatizar que a História do Kongo é dinâmica, pretendendo analisar as continuidades e rupturas numa perspectiva braudeliana da longa duração.

O livro começa por tentar identificar a formação da chefatura de Mbanza Kongo, cuja origem é difícil de precisar graças à complexidade de um intenso movimento migratório, impulsionado por diversas causas, entre as quais a necessidade de agricultura itinerante devido ao desgaste do solo, além de variantes como mortalidade anormal ou morte do chefe do clã.

$\mathrm{O}$ autor procura caracterizar as estruturas de parentesco da sociedade Kongo e seu sistema de sucessão submetido à linhagem matrilinear, ainda que sob alianças políticas estabelecidas patrilocalmente, ao mesmo tempo em que resgata as origens da sociedade Kongo. Analisa exaustivamente estes movimentos de sucessão e alianças, decifrando suas regras segundo a descendência matrilinear aliada aos elos patrilaterais, que determinam o controle sócio-político da área extensa e suas relações dinâmicas de poder. Enfatiza diversas vezes que as regras de parentesco biológico ou sociológico não são estáticas, mas redefinidas em vários momentos, o que gera conflitos ligados à sucessão e à herança. 
Dentro de uma linhagem, explica o autor, o chefe detém prestígio e funções sagradas, mas seu poder é regulado pelo coletivo e assim, ainda que tenha subordinados, ele deverá agir segundo os aconselhamentos do grupo. Dessa forma, o chefe exerce sua autoridade sobretudo no exterior do grupo, autoridade esta que é, antes de tudo, de ordem simbólica. Ao chefe é facultado a palavra como sagrada, ele é responsável pela fala em nome do grupo, pelo discurso e, como representante do coletivo, é também o guardião das tradições, a começar pelos ritos de investidura e insígnias de poder.

Nesse sentido, o autor critica análises que tratam as sociedades Kongo e sua relação com seus chefes sob termos como "vassalagem" ou "feudalismo", pois "não existe submissão de clientela de vassalagem". Ao contrário disso, o chefe é responsável por dividir os seus subordinados em grupos e dar-lhes uma parcela de terra, diferenciando-se do que seria uma sociedade feudal.

António Custódio Gonçalves chama a atenção ainda para a confusão presente nos relatos desde o século XVI em tratar a chefatura de Mbanza Kongo como "reino do Kongo" à semelhança do reino de Portugal, esclarecendo que os "reinos" ou "províncias" identificados pelos cronistas eram na verdade, "grupos de linhagem ligados por laços de parentesco e por troca de presentes com o Chefe preeminente de linhagem, sucessor do chefe originário comum.” Ou seja, os cronistas identificaram, num momento de transição dos grupos, uma certa soberania do chamado "reino do Kongo", uma vez que as outras chefaturas reconhecidas como "províncias" encontravam-se em fase de estruturação, entretanto elas não tinham com Mbanza Kongo uma relação de sujeição, mas de aliança e troca. Para o autor, os povos Kongo tiveram papel determinante na história da África Central atlântica "sobretudo pela potente originalidade de uma cultura que soube impor-se a tantos grupos marginais ou assimilar os mais diversos contributos, sem perder o essencial do seu carácter."

Na segunda parte do livro, o autor discorre sobre o que considera o primeiro momento de ruptura por ele analisado. Trata-se do período em que o "rei do Kongo" era D. Afonso I (1509-1540), católico fervoroso, responsável por promover uma intensa integração dos preceitos religiosos cristãos e das normas sócio-políticas portuguesas na região. Esse evento não significou, no entanto, a perda total das tradições, ao contrário, caracterizou-se como um dos "períodos mais significativos da criatividade sociológica do reino do Kongo para responderem aos desafios da simbiose da tradição e da modernidade." 
O empenho de Portugal para transformar o Reino do Kongo "ponta de lança da conquista espiritual da África" aliado aos interesses de D. Afonso, para quem a aproximação com a monarquia portuguesa representava uma maneira promissora de manutenção e centralização do poder, foram a fórmula para uma acentuada mudança na sociedade Kongo. Ainda assim, Custódio Gonçalves analisa D. Afonso como ícone de um dos momentos em que a tradição mostrou-se inabalável, uma vez que os rótulos e organização social portugueses eram artificiais e impróprios para a sociedade Kongo.

Com D. Afonso, cria-se a primeira escola primária elementar, onde ensinava-se a língua portuguesa por intermédio de um professor congolês que teria ido para Lisboa com Diogo Cão no retorno da primeira embarcação portuguesa a aportar na região. Também é sob a autoridade de $\mathrm{D}$. Afonso que tem lugar o Regimento de D. Manuel I da monarquia portuguesa, a partir do qual fundamenta-se a ação política e cultural portuguesa no Kongo, instruindo a ação missionária, regulamentando a escravidão e instituindo os cargos políticos segundo os preceitos portugueses: príncipes, marqueses, condes etc.

Custódio Gonçalves observa que "os instrumentos necessários à governação centralizada e individualizada, trazidos pelos regimentos, não se coadunavam perfeitamente com as concepções e as práticas tradicionais da autoridade e do poder." A nova religião e o novo modo de administrar que D. Afonso queria implantar privilegiavam o indivíduo em detrimento do coletivo, o que segundo o autor, teria provocado revolta contra as possíveis transformações. Para ele, a "simbolização e a normatividade política tradicionais foram subvertidas, com a emergência do absolutismo e do poder centralizado dos chefes instituídos contra os chefes tradicionais e representantes naturais das linhagens."

Com a morte de D. Afonso em 1540, inicia-se um longo período de crise política que duraria até fins do século XVII. Oscilam-se períodos de concentração de poder do "rei do Kongo" e períodos de poder mais difuso, com o "consequente revigoramento da autoridade tradicional dos chefes naturais das matrilinhagens." Durante o século XVII, a presença holandesa em Luanda e o êxodo dos portugueses para Angola contribuiriam para um período de tensões.

$\mathrm{Na}$ terceira parte do livro, o autor detém-se sobre os mecanismos de revitalização das estruturas tradicionais que se mantiveram mesmo após todas as mudanças empreendidas por D. Afonso e as influências européias. Uma das chaves para entender esse momento de revitalização é o fenômeno da Kimpa Vita, que deu origem ao movimento conhecido como antonionismo, analisado 
com maestria por Custódio Gonçalves. A jovem Beatriz Kimpa Vita, precursora do movimento, dizia ser a encarnação de Santo Antônio, proclamado por ela como "segundo Deus" e restaurador do reino do Kongo. Consequentemente, denominava-se a si mesma a restauradora da sociedade Kongo.

Ela se utilizava de elementos cristãos, sem no entanto deixar de fazer pesadas críticas e re-significações, uma vez que reclamava não lhes ser apresentado um Cristo negro pelo catolicismo e julgava ser o batismo, o casamento e a confissão "esvaziados de sentido". Kimpa Vita retomou ainda alguns elementos tradicionais da sociedade Kongo como o retiro à floresta, momento em que se comunicava com seus antepassados e cultuava o "espírito do solo", símbolo da fecundidade e da fertilidade.

Para o autor, esse episódio revela caminhos para se entender inúmeras facetas da sociedade Kongo. Kimpa Vita foi, a seu ver, o segundo momento de "criatividade sociológica", que sucedeu a um período de crise desencadeado com a Batalha de Ambuíla em 1665, que traria instabilidade político-social devido a rivalidades linhageiras, ainda que as lutas de linhagem fossem parte integrante da vida do próprio grupo. Custódio Gonçalves identifica similaridades entre o movimento do antonionismo e o período de Afonso I, começando com o fato de que ambos os movimentos apresentaram-se como rearranjos após um período de crise. "Paradoxalmente, Kimpa Vita assimila elementos da cultura ocidental para renovar a tradição e recorre à tradição renovada para dominar esta assimilação."

Kimpa Vita é uma chave importante para que o autor demonstre o quanto é preciso estudar a História do Kongo e Angola em suas próprias especificidades, onde não há distinção entre os níveis políticos, sociais e simbólicos. O chefe de uma linhagem é um líder político e ao mesmo tempo uma figura sagrada, simbolicamente ligado aos ancestrais.

O chamado antonionismo não morreu com Kimpa Vita, que ardeu em chamas católicas junto ao seu companheiro em 1706, mas segundo o autor, foi um fenômeno precursor de movimentos messiânicos recorrentes ao longo do tempo até os dias de hoje. Movimentos que trazem, como analisa Custódio Gonçalves, uma retomada às tradições que, na atualidade, ao lado de manifestações literárias, apresentam-se revestidos de forte cunho nacionalista.

Nesse sentido, o autor apresenta-nos o último capítulo de seu livro como uma reflexão sobre o processo de construção (ou re-construção) da nação angolana pós-colonial. Um texto que se descola no tempo em relação ao restante 
do livro, mas cujo ponto de convergência seria a retomada de Kimpa Vita como um fenômeno messiânico recorrente em diferentes momentos na longa duração histórica e "latente a cada nova época de crise". Um texto relativamente panfletário sobre as possíveis contribuições das ciências sociais e humanas nesse processo histórico pelo qual passa Angola, com suas especificidades e sua capacidade em se tornar uma democracia. Assim finaliza o livro, como quem viveu na região, não como um estrangeiro, apesar de reconhecer sê-lo inevitavelmente, mas envolvido intensamente com as questões que lhe são próprias. 